\title{
Review \\ Clinical review: Allocating ventilators during large-scale
disasters - problems, planning, and process
} John L Hick ${ }^{1,2}$, Lewis Rubinson ${ }^{3}$, Daniel T O'Laughlin ${ }^{1,4}$ and J Christopher Farmer ${ }^{5}$

\author{
1 University of Minnesota Medical School, Minneapolis, MN, USA \\ 2Emergency Medicine MC 825, Hennepin County Medical Center, 701 Park Ave. S., Minneapolis, MN 55415, USA \\ ${ }^{3}$ Disaster Medicine Director, Public Health- Seattle \& King County, 999 3rd Avenue, Suite 1200, Seattle, WA 98104, USA \\ ${ }^{4}$ Abbott Northwestern Hospital, 2925 Chicago Ave. S. Emergency Medicine, Minneapolis, MN 55407, USA \\ ${ }^{5}$ Mayo Clinic School of Graduate Medical Education. Division of Critical Care Medicine, Mayo Clinic, Rochester, MN USA 55905, USA
}

Corresponding author: John L Hick, john.hick@co.hennepin.mn.us

Published: 19 June 2007

This article is online at http://ccforum.com/content/11/3/217

(c) 2007 BioMed Central Ltd
Critical Care 2007, 11:217 (doi:10.1186/cc5929)

additional supplies and equipment may not be readily obtainable. For some equipment and medications, traditional allocation units can be reduced and substitutions are possible (for example, oral instead of intravenous medications) to allow all in need to have adequate access to resources rather than fewer to have unlimited access.

For a number of complex, durable medical devices such as mechanical ventilators, there are few acceptable alternatives $[7,8]$. In some circumstances, temporizing measures such as manually ventilating patients may be adequate. Such a strategy is likely to be inadequate for disasters requiring days of ventilatory support, especially for people with severe respiratory failure. Even if enough mechanical ventilators were available to meet the need of hundreds or thousands of additional critically ill patients in a community, critical care personnel may be in too short of supply to withstand the demands of pervasive disasters, like a severe influenza pandemic. The critical care response to a severe influenza pandemic will be further challenged by insufficient external relief and augmentation assets; the critical care needs of all communities may not be met [9-11]. Under these circumstances, triage of patients who are newly requiring critical care interventions and of those who have already received some degree of definitive medical care may be required in order to justly allocate the limited functional capability of mechanical ventilation at a health care facility. To optimize these decisions, there are several key constructs that hospitals must discuss and predefine:

1. A well-practiced incident management system (for example, Hospital Incident Command System) [12] that is congruent with the National Incident Management System [13] should be in place in area health care facilities and public safety entities. A congruent standard of care within 
the institution as well as in the affected geographic area can be achieved only by prioritizing resource allocation and cooperatively working with local public health and other agencies in an incident management framework [10,14,15].

2. A clinical care committee (or other similar group within the planning section) must work with the institution's incident commander on a daily basis. This group will determine which services a health care facility will provide and what adaptations must be made to provide these critical services based on the demand and the resources available [10].

3. A triage team composed of a few individuals with expertise in critical care and relevant disciplines (for example, infectious disease during a pandemic). To determine how best to allocate the available assets, the team can examine data from patients currently being ventilated and those who require ventilation [10].

4. Decision tools that the triage team can apply in order to minimize bias and thus most fairly allocate the ventilators at the institution.

5. Formal processes and recommendations for palliative and end-of-life care at the institution.

A few recent publications have examined both the process [10] of decision-making and possible decision tools for burns [16] and mechanical ventilation [9,11]. Prognostic data can be used to triage patients after radiation exposures $[17,18]$. Research in trauma mass casualty triage is scant $[19,20]$ and is often based on military experience [21-23]. Pandemic influenza triage has been examined in the context of prediction of the need for hospital admission and mortality, but not in terms of resource triage [24].

Given the heterogeneity of possible events and agents that may result in large numbers of patients requiring critical care, no single tool or scale can be expected to provide adequate decision-making power. There are also many injury and disease states (such as pandemic influenza) for which decision tools will have to be developed and validated during the event as evidence of disease epidemiology and patient response to therapy accrues. The availability (or lack) of accurate and rapid testing for certain diseases may also have significant impact on the ability to predict outcome or make definitive diagnoses $[25,26]$.

Thus, the focus at the hospital level should be on establishing the process that will be followed at the health care facility and within the geographic region in a resource-scarce situation, knowing that the specific decision support tool may be eventdriven. This is crucial because regardless of the origin of the decision tool (national government, local/regional government, specialty medical society, and so on) the implementation of the tool occurs at the hospital level. This article will discuss a sample process for resource-scarce situations and a prototype decision matrix for allocating ventilators.

\section{Ethical and operational goals}

Although in-depth consideration of the ethical and operational issues involved in allocation decisions is beyond the scope of this paper, a few key assumptions should be stated. The reader is referred to other sources for additional discussion [27-38].

- In a disaster situation, the focus of medical care shifts from the needs of the individual (autonomy) to the needs of the community as a whole (distributive justice) so that the 'greatest good for the greatest number' is the goal. Actual application of this ethical principle is complex and is the subject of current debate and interpretation. It is customary for the critical care physician to heavily weigh patient and family wishes and subjective considerations in determining 'futile care'. This calculus is reversed during a disaster so that the weight is on objective prognostic criteria and less on subjective and individual patient factors (Table 1). This shift in priorities will require significant pre-event education and training for critical care staff.

- An additional overall goal-which has received inadequate attention-should be to provide patients as much comfort and dignity as the situation allows regardless of other interventions available.

- If a specific scarce resource that is life-saving or potentially life-saving is not available in sufficient quantity to meet patient demand despite all efforts to obtain adequate resources from other local, regional, and national partners in a timely manner and

- No temporizing measures are available (for example, when manual ventilation is not an option) and

- Resource cannot be 'titrated' (for example, drugs or oxygen) or substituted (for example, oral instead of intravenous antibiotics) and

- All available resources and resource surrogates (for example, bi-level positive airway pressure and anesthesia machines) have been repurposed to manage respiratory failure, but these efforts are inadequate to meet the demand, then

- The overarching goal is to allocate facility resources to those likeliest to benefit, taking into consideration [39]:

- Medical prognosis

- Underlying disease

- Expected duration of resource need

- Duration of benefit

- Quality of life after intervention (unfortunately a criteria subject to significant bias and interpretation).

- Any other considerations involving weighing subjective measures (for example, the role of the patients, including health care workers, in the community) must be determined by public discussion, and a means for a lay panel/team to assess these factors must be available if the community determines that this is important. Medical personnel should not apply 
Table 1

\begin{tabular}{lll} 
Contrasting medical decision-making in resource-adequate versus resource-poor situations \\
\hline Limiting medical care & Resource-adequate situation & Resource-poor situation \\
\hline Focus & Patient autonomy & Community needs \\
Relationships & Caregivers invested with family & Caregivers unknown to family \\
Patient condition & End of life & NOT at end of life \\
Decision made & Days to weeks & Hours \\
Prior care & Exhaustive & Little to none \\
Subjective inputs & Critical & Minimal \\
Key decision-maker & Family and caregivers & 'Triage' physician or team
\end{tabular}

subjective criteria in their decision-making. This is consistent with the American Medical Association position on scarce-resource allocation [39].

- Due to government control of practitioner licensure and liability, any such system of resource allocation should be part of a planned state/province or national government response to an overwhelming emergency. As part of this planned response, medical providers must be protected legally for making these difficult decisions. Under no circumstances should a health care facility be in a position of having to make systematic triage decisions without activation of state or national emergency health powers $[10,40]$ to enable legal protection for providers who in good faith are complying with pre-existing response plans or event-specific state and jurisdictional directives.

\section{Allocation decision-making}

The first goal of health care emergency preparedness planning is to augment the actual capacity and capabilities of the system $[5,10,14,41-44]$. Should this capacity prove inadequate to meet the demands of a catastrophic disaster, the secondary goal is to make the system 'fault-tolerant' or to 'bend' rather than 'break'-making the minimum adaptations necessary to cope with resource shortages (Table 2).

Many incidents with multiple victims may require some degree of adaptation or resource triage. (For example, in a car crash with multiple victims, who goes to computed tomography or the operating room first?) However, these situations are generally mitigated rapidly and do not usually require a systematic, ongoing, and institution-wide process to determine what medical care can be provided based on the demand and the resources available. Resource stockpiling, staff cross-training, and altering staff responsibilities and documentation requirements can help increase the capacity for these incidents and thus prevent a resource-scarce situation, as can timely resource requests based on anticipation of deficits prior to their actual occurrence $[4,5,10,14$, 41-44].
When an event is ongoing and when it is likely that resources will continue to be inadequate to meet immediate or future needs, changes to the usual process of patient care become necessary to provide sufficient medical care relative to the resources available and the patient demand. The goals are to make the minimum adaptive changes necessary, with an emphasis on administrative changes (for example, limiting documentation and having non-clinical staff serve meals) rather than clinical changes (for example, triaging persons away from the emergency department and allocating limited ventilators), and to reverse the adaptations as soon as adequate resources become available [10].

As part of this response, mobilization of available health care and non-health care personnel to provide patient care should occur. Internally, staff should be reassigned and roles redefined to maximize patient care time. External workforce augmentation via agreements with the Medical Reserve Corps and other sources of personnel augmentation (such as Federal Disaster Medical Assistance Teams) should be preplanned with relevant agencies. Also, this planning should include appropriate just-in-time training for all personnel taking on unfamiliar tasks and should credential, privilege, and assign mentors to outside personnel assisting in the institution. A clinical care committee or similar group (Table 3) must review the facility resources and community needs and determine what services will be offered, how and where these services will be provided, and by what process triage decisions will be made should that become necessary [10].

The process for institutional response (a sample of which is detailed in Table 4) will vary depending on the size and mission of the facility. For this to be successful, timely and accurate unit and individual patient data must be available to the committee. Note that this represents an ideal situation. In times of disaster, the incident commander must be able to account for the actions required to fairly institute such protocols even if the full clinical care committee is unavailable. However, the full committee as determined by the institution is critical for effective planning, training, and 
Table 2

\section{Fault-tolerant systems}

'Fault-tolerance or graceful degradation is the property that enables a system to continue operating properly in the event of the failure of some of its components. If its operating quality decreases at all, the decrease is proportional to the severity of the failure, as compared to a naively designed system in which even a small failure can cause total breakdown. Fault-tolerance is particularly sought after in high-availability or life-critical systems' [61].

Many systems must be engineered to be fault-tolerant. The same principles must be applied to critical services provided by hospitals during a disaster. The following strategies can be applied to manage demand that would otherwise prompt system failure:

- Engineered system failure - Similar to a circuit breaker, this allows system components to fail in order to prevent catastrophic damage to the system as a whole. An example might be a hospital switchboard that gives preference to internal hospital calls (rather than to calls from external sources) to preserve internal communications during an emergency.

- Redundancy - Having adequate duplicate supplies or services available in case of failure (for example, extra intravenous pumps or ventilators).

- Diversity - Having many ways of providing the same service, but via different techniques (for example, triaging patients in multiple areas of the hospital: emergency department, lobby areas, and so on).

\section{Table 3}

\section{Clinical care committee sample membership}

A clinical care committee (the members are predetermined for toxic, infectious, and trauma situations) is convened. During a pandemic, for example, this committee might consist of some or all of the following at a large facility [11]:

- Administrator or designee

- Medical director

- Infection control

- Infectious disease

- Critical care

- Emergency medicine

- Pediatrics

- Nursing supervisor

- Respiratory care supervisor

- Hospital ethicist (if possible)

- Legal counsel

- Community representative (if possible, similar to Institutional Review Board role)

- Other (may include lab, radiology, bioelectronics, and pharmacy)

drilling of the scarce-resource response to ensure that the institutional plan is realistic and sound.

The importance of incident command awareness of and facility with these situations and the adaptive structures and mechanisms that exist at the institution cannot be underemphasized. Furthermore, critical care staff should be aware of the process for decision-making when demand exceeds resources so that they are prepared to act, rather than spend valuable time reacting to a completely new health care paradigm.

\section{Decision support tools}

Determining which patients shall receive mechanical ventilation when triage is required will be a difficult process from both a clinical and a psychological perspective. There are currently no models that provide a framework for considering what we believe are three key areas that should be evaluated when considering a patient for critical care services:

- Organ system function (and severity of impairment)

- Duration of ventilator use and duration of benefit related to:

- Disease-specific predictors (for example, pandemic influenza)

- Underlying disease (for example, severe chronic obstructive pulmonary disease)

- Response to a trial of mechanical ventilation (if received based on above factors)

An ideal decision tool for allocating mechanical ventilation would likely be graphically clean, easy to apply, objective, accurate, reproducible, and predictive of resource use and outcome and would not discriminate against vulnerable populations. No such tool is available, but a matrix (developed as a discussion draft for the Minnesota Department of Health) that captures the core elements above is presented in Figure 1. The matrix provides a supportive framework for clinical decision-making but allows the 'best method/ evidence available' to be used within the matrix boxes and adjusted on an ongoing basis.

A standardized method of assessing multi-organ function (and failure) is a key step in determining prognosis, and several scoring systems have significant ability to predict mortality. Prior authors have suggested using the Sequential Organ Failure Assessment (SOFA) [45] in a strategy considering underlying disease and organ failure $[9,11]$.

The SOFA score has wide validity across a range of patient pathologies and is easy to calculate, using few laboratory and no invasive hemodynamic variables. Changes in SOFA scores over time may be of value in determining prognosis as well [46-55]. Notably, SOFA and most scoring systems have not been validated in pediatric populations. The SOFA score provides an objective result relating to patient prognosis and is a numeric that may be compared between institutions and 


\section{Table 4}

\section{Sample process for healthcare facility response during resource-poor situation}

- Incident commander recognizes that systematic changes are or will be required to allocate scarce facility resources and that no regional resources are available to offset demand.

- Planning chief gathers any guidelines, epidemiologic information, resource information, and regional hospital information.

- Clinical care committee reviews facility/regional situation and examines the following:

- Alternate care sites - Can additional areas of the building or external sites be used for patient care? (This should be planned in advance.)

- Medical care adaptations (for example, use of non-invasive ventilation techniques, changes in medication administration techniques, and use of oral medications and fluids instead of intravenous).

- Changes in staff responsibilities to allow specialized staff to redistribute workload (for example, floor nurses provide basic patient care in the intensive care unit while critical care nurses 'float' and troubleshoot) [5] and/or incorporate other health care providers, lay providers, or family members where practical.

- Triage plan describing how the use of scarce resources at the facility (emergency department [ED] resources, beds, operating rooms, and ventilators) will be allocated. (What level of severity will receive care? What tool or process will be used to make decisions when there are competing demands for the same resource?)

- Community/regional strategies to cope with the situation and how the institutional response contributes to those efforts.

- Committee summarizes recommendations for next operational period and determines meeting and review cycles for subsequent periods (may involve conference calls or similar means to avoid face-to-face meetings during a pandemic).

- Incident commander approves committee recommendations as part of incident action plan. Plan is operationalized. Public information officer communicates updates to staff, patients, families, and the public.

- Current inpatients, patients presenting to the hospital, and their family members are given verbal and printed information (ideally by the triage nurse in the ED or, for inpatients, by their primary nurse or physician) explaining the situation and that resources may have to be reallocated, even once assigned, in order to provide care to those who will most benefit. A mechanism for responding to patient/family questions and concerns should also be detailed.

- Security and behavioral health response plans should be implemented.

- Triage plan (which may affect all units equally or some more than others) implemented:

- ED/outpatient screening of patients (and denial of service to patients either too sick or too well to benefit from evaluation/admission) based on guidance disseminated by the clinical care team.

- Tertiary triage team (ideally NOT the physicians directly providing the patients' care and ideally two physicians of equal 'rank' in the institution) considers situations in which there are competing patient demands for a scarce resource. The resource should be assigned as follows:

When two patients have essentially equal claim to the resource, a 'first-come, first-served' policy should be used.

When, according to guidelines or the triage team's clinical experience, the claim to the resource is clearly not equal, the patient with a more favorable prognosis/prediction shall receive the resource.

The triage team should ask for and receive whatever patient information is necessary to make a decision but should NOT consider subjective assessments of the quality of the patients' life or value to society and, in fact, should ideally be blinded to such information when possible.

- A 'bed czar' (under the Hospital Incident Command System, this is the inpatient unit leader) should be appointed to make final decisions on bed assignments. This individual should have access to real-time inpatient and outpatient system status and, when needed, patient clinical information.

- Whenever a decision is made to reallocate a ventilator or similar critical resource, the treating physician and family should be provided with the grounds for the decision (which should be documented for the record at the facility) and a rapid appeals process if there is additional or new information that the family or a treating physician feels would affect the decision.

help inform regional resource allocation decisions. These results may be of limited value during a pandemic, however, as large numbers of patients may begin to cluster around lower mean scores.

Unfortunately, because SOFA and other scoring systems (APACHE [Acute Physiology and Chronic Health Evaluation], MPM II [Mortality Probability Models II], and so on) were derived and validated on cohorts, they are less accurate in predicting the response of individual patients [56]. This inaccuracy compounds the difficulty in deciding whom to offer ventilation as there would need to be a substantial difference (for example, 25\%) in survival advantage predicted by the scoring system to justify removing one patient from a ventilator and giving the resource to another. Furthermore, this use repurposes these prognostic systems to tasks for 
Figure 1

\begin{tabular}{|c|c|c|c|}
\hline & Ventilator reallocated & $\rightarrow$ & Patient keeps ventilator \\
\hline 1. Organ system functiona & $\begin{array}{l}\text { High potential for death according } \\
\text { to predictive modela }\end{array}$ & $\begin{array}{l}\text { Intermediate potential for death } \\
\text { according to predictive model }\end{array}$ & $\begin{array}{l}\text { Low potential for death according } \\
\text { to predictive model }\end{array}$ \\
\hline \multirow[t]{2}{*}{ 2. Duration of benefit/prognosis } & $\begin{array}{l}\text { a. Poor prognosis based on } \\
\text { epidemiology of specific } \\
\text { disease/injury (for example, } \\
\text { pandemic influenza) }\end{array}$ & $\begin{array}{l}\text { a. Indeterminate/intermediate } \\
\text { prognosis based on epidemiology } \\
\text { of specific disease/injury }\end{array}$ & $\begin{array}{l}\text { a. Good prognosis based on } \\
\text { epidemiology of specific } \\
\text { disease/injury }\end{array}$ \\
\hline & $\begin{array}{l}\text { b. Severe underlying disease } \\
\text { with poor short-term prognosis }\end{array}$ & $\begin{array}{l}\text { b. Severe underlying disease with } \\
\text { poor long-term prognosis and/or } \\
\text { ongoing resource demand (for } \\
\text { example, home oxygen-dependent, } \\
\text { dialysis-dependent) }\end{array}$ & b. No severe underlying disease \\
\hline 3. Duration of need & $\begin{array}{l}\text { Long duration - for example, } \\
\text { acute respiratory distress } \\
\text { syndrome, particularly in setting } \\
\text { of pre-existing lung disease } \\
\text { (estimate more than } 7 \text { days on } \\
\text { ventilator) }\end{array}$ & $\begin{array}{l}\text { Moderate duration - for example, } \\
\text { pneumonia in healthy patient } \\
\text { (estimate } 3 \text { to } 7 \text { days on } \\
\text { ventilator) }\end{array}$ & $\begin{array}{l}\text { Short duration - flash pulmonary } \\
\text { edema, chest trauma, other } \\
\text { conditions anticipating less than } \\
3 \text { days on ventilator }\end{array}$ \\
\hline $\begin{array}{l}\text { 4. Response to mechanical } \\
\text { ventilation }\end{array}$ & $\begin{array}{l}\text { Worsening ventilatory } \\
\text { parameters over time }\end{array}$ & $\begin{array}{l}\text { Stable ventilatory parameters } \\
\text { over time (judged by clinician as } \\
\text { failure to improve after adequate } \\
\text { trial of mechanical ventilation } \\
\text { based on disease process) }\end{array}$ & Improving ventilatory parameters \\
\hline
\end{tabular}

Compared to other patient(s) requiring and awaiting mechanical ventilation, does this patient have significant differences in prognosis or resource use in one or more categories above that would justify reallocation of the ventilator?

aThe SOFA (Sequential Organ Failure Assessment) score is a currently preferred scoring system based on type of data required and ease of calculation.

${ }^{\mathrm{b}}$ Examples of underlying diseases that predict poor short-term survival include (but are not limited to) the following: congestive heart failure with an ejection fraction of less than $25 \%$ (or persistent ischemia unresponsive to therapy or ischemia with pulmonary edema); acute renal failure requiring hemodialysis (related to illness); severe chronic lung disease, including pulmonary fibrosis, cystic fibrosis, or obstructive or restrictive diseases requiring continuous home oxygen use prior to onset of acute illness; immunodeficiency syndromes with evidence of opportunistic pathogen infection; central nervous system, solid organ, or hematopoietic malignancy with poor prognosis for recovery; cirrhosis with ascites, history of variceal bleeding, fixed coagulopathy, or encephalopathy; acute hepatic failure with hyperammonemia; acute and chronic and irreversible neurologic impairment that makes patient dependent for all personal care (for example, severe stroke, congenital syndrome, persistent vegetative state, and severe dementia).

${ }^{\circ}$ Changes in oxygenation index $(\mathrm{OI})$ over time may provide comparative data, though of uncertain prognostic significance. OI $=\mathrm{MAWP} \times$ $\mathrm{FiO}_{2} / \mathrm{PaO}_{2}$, where MAWP is mean airway pressure, $\mathrm{FiO}_{2}$ is inspired oxygen concentration, and $\mathrm{PaO}_{2}$ is arterial oxygen pressure. $\mathrm{PaO} \mathrm{O}_{2}$ may be estimated from peripheral oxygen saturation by using the oxygen dissociation curve if blood gas measurements are unavailable.

Decision matrix for ventilator allocation during resource-poor situation.

which they were not designed and which were not considered during the original mortality 'cut-score' determinations. Thus, using a numeric score based on organ function is not likely to be a satisfactory sole discriminator (unless the difference between patient scores is large) since it is not enough to 'rank' patients in order to place them on available ventilators as there are likely none available.

Prospective validation of the use of the SOFA score and other scoring systems for these purposes should be a focus of research efforts. Awaiting better prognostic tools, we would recommend the SOFA score due to its ease of calculation and its reliance on a minimum of laboratory testing.

Duration of benefit and duration of resource need are likely to involve more subjective interpretation of data and are thus more fraught with ethical peril. However, we feel that these considerations are important when determining ventilator allocation.

Assessment of likely duration of benefit and duration of need for ventilation must account for both current disease-specific prognostic factors and underlying disease states (particularly ones that severely shorten life span or impact quality of life). Prognosis is easier to estimate for some pathologies (pulmonary contusion from trauma and severe burns) but less so for disease states such as pandemic influenza, in which the age groups affected, response to treatment, and other factors are unknown. Assessment of expected duration of mechanical ventilation aims to successfully manage more patients with the same resource over a prolonged event, thus offering greater community benefit, but may be invoked only when there is a clear-cut difference between patients (for 
example, pulmonary edema secondary to missed hemodialysis versus acute respiratory distress syndrome [ARDS]). Though important, these predictions are imprecise and often may be subject to bias.

Consideration of significant underlying disease states and their effect on patient life span, quality of life, duration of resource benefit, and resource demands is important for determining whether there is a substantial difference between the patients requiring the therapy, but is most subject to interpretation bias and is least specific. Triage based on underlying disease states aims to ventilate patients who do not have diseases that would predict a protracted or poor response to treatment or limited duration and scope of benefit following recovery. Use of hospice and other welldefined 'quality of life' standards and longevity predictors may be helpful strategies, and this is being explored currently by a task force in King County, WA, USA (L Rubinson).

Patients already on a ventilator or those who are offered a trial of mechanical ventilation (and it should be viewed as a therapeutic trial rather than a resource 'assignment' in a resource-scarce situation) should be reassessed on an ongoing basis. If their condition (and prognosis) continues to worsen (or simply fails to improve after an appropriate duration of time given their disease state), this should be weighed when considering whether to continue ventilatory support. An objective tool to assess response to mechanical ventilation is needed and should be developed. The oxygenation index has been correlated with mortality in certain groups and is one of the few calculations available that may have utility as an objective marker as it changes over time. Although its applicability to triage is unknown, a worsening oxygenation index over time may provide helpful information to the critical care physician and triage team about the benefit of mechanical ventilation [57-60].

Thus, triage team members need to compare a variety of factors when making a decision about ventilator allocation. For example, if patient ' $A$ ' is the most marginal of currently ventilated patients (based on assessment of current prognostic and other variables) and now patient ' $\mathrm{B}$ ' requires a ventilator (but none are available), one must determine whether, based on the matrix, there is a clear-cut reason that patient $A$ should be taken off the ventilator so that patient $B$ can receive it. The clinician proceeds stepwise through the tool to compare the patients. If there is a clear-cut difference found favoring patient $A$ or $B$ (for example, green versus red category), an allocation decision can be made. But if there are no green versus red discriminators, the matrix tool results as a whole should be considered (for example, blue versus red in several categories) in order to determine whether there is a clear-cut balance favoring one patient over the other. Unless (in the opinion of the team) there is a substantial advantage favoring patient $B$ once these factors are weighed, patient $A$ continues on the ventilator.
Note that if patient B were on the ventilator, the same assessment might yield a determination that patient $B$ should stay on the ventilator. Because the outcome of a decision to terminate ventilatory support results in harm (likely death), the difference in prognosis/demand/duration likewise should be clear-cut for ventilator reassignment to occur; otherwise, 'first-come, first-served' applies.

Teams may find it helpful to track patient data and history factors on the matrix tool so that these can be maintained for ongoing comparisons/updates and changes tracked easily over time. Note that as clinical conditions change, patients $C$ or $\mathrm{D}$ may become the most marginal recipient of therapy and thus would be the basis for comparison rather than patient $A$. It is extremely important that the triage team be aware of evolving changes in patients' clinical conditions and be able to maintain a relative 'rank list' of intensive care unit patients on ventilators relative to their clinical condition and other variables.

The science of triage (in particular, tertiary triage) is nascent, and we believe that our suggestions above will soon be replaced by more robust and researched strategies. Predictive models that are more specific may be introduced into the 'disease-specific prognosis' category (for example, neurotrauma, burns, and ARDS). The matrix allows better predictive systems to be incorporated without changing the basic framework or factors considered. This matrix may also be used to consider whether to offer other therapies to patients (such as intensive care admission), but there may be other simpler tools that rely on clinical assessment and that could be used in an emergency department setting to accomplish this type of secondary triage (after initial stabilization).

Additionally, although the matrix attempts to incorporate relevant variables for triage of mechanical ventilation, it has not been tested for reproducibility between practitioners and patient groups, which limits its inherent validity. However, we feel that this tool represents a significant step forward from prior empiric efforts and reflects realistic considerations that must be balanced when making these difficult decisions. It is also a concrete reference point for discussions about limiting care in resource-scarce situations, as theoretical discussions about clinical care committees and the ethical basis of withdrawing and withholding medical care may miss practical issues and problems that the institution would face in such a circumstance.

\section{Conclusion}

Critical care providers are in a position to help inform and lead hospital discussions about resource allocation decisions, critical care surge capacity, and the exercising of these plans at their facility. Indeed, their absence from the process predicts failure of the systems in crisis. Additionally, critical care physicians must understand that the patients 


\section{This article is part of a thematic series on Disaster management edited by J Christopher Farmer.}

Other articles in this series can be found online at http://ccforum.com/articles/ theme-series.asp?series=CC_Disaster

being hospitalized during such an event will be far sicker than the usual caseload and must determine in advance as part of their departmental plan how their limited nursing and physician staff would be extended (consultative role, documentation, and external consultations for hospitals not used to providing long-term critical care) [5].

Finally, critical care physicians must exert leadership to ensure that their institution is prepared for a situation in which critical care resources, including mechanical ventilation, would be inadequate to meet the community need. Determining 'futile care' in the context of daily patient care is far different from a resource-poor situation (Table 1), and critical care physicians can assist their hospital ethics committee and administration in developing plans and providing education that will facilitate such a paradigm shift should that become necessary. We urge that these conversations begin now, so that should such a tragic situation develop, providers and the public alike understand our limitations, our goals, and the systems that we have designed to make the best of our limitations.

\section{Competing interests}

The authors declare that they have no competing interests.

\section{References}

1. Halpern NA, Pastores SM, Greenstein RJ: Critical care medicine in the United States 1985-2000: an analysis of bed numbers, use, and costs. Crit Care Med 2004, 32:1254-1259.

2. Halpern NA, Pastores SM, Thaler HT, Greenstein RJ: Changes in critical care beds and occupancy in the United States 19852000: differences attributable to hospital size. Crit Care Med 2006, 34:2105-2112.

3. Critical Care Units: A Descriptive Analysis. 3-1-2005. Des Plaines, IL: Society of Critical Care Medicine; 2005.

4. Rubinson L, Branson RD, Pesik N, Talmor D: Positive-pressure ventilation equipment for mass casualty respiratory failure. Biosecur Bioterror 2006, 4:183-194.

5. Rubinson L, Nuzzo JB, Talmor DS, O'Toole T, Kramer BR, Inglesby TV: Augmentation of hospital critical care capacity after bioterrorist attacks or epidemics: recommendations of the Working Group on Emergency Mass Critical Care. Crit Care Med 2005, 33:2393-2403.

6. Daugherty EL, Branson R, Rubinson L: Mass casualty respiratory failure. Curr Opin Crit Care 2007, 13:51-56.

7. Neyman G, Irvin CB: A single ventilator for multiple simulated patients to meet disaster surge. Acad Emerg Med 2006, 13: 1246-1249.

8. Branson RD, Rubinson L: A single ventilator for multiple simulated patients to meet disaster surge (letter). Acad Emerg Med 2006, 13:1352-1353.

9. Hick JL, O'Laughlin DT: Concept of operations for triage of mechanical ventilation in an epidemic. Acad Emerg Med 2006, 13:223-229.
10. Agency for Healthcare Research and Quality (AHRQ): Providing Mass Medical Care with Scarce Resources: A Community Planning Guide. AHRQ Publication No. 07-0001, November 2006. Edited by Phillips S, Knebel A. Rockville, MD: AHRQ. [http:// www.ahrq.gov/research/mce/].

11. Christian MD, Hawryluck L, Wax RS, Cook T, Lazar NM, Herridge MS, Muller MP, Gowans DR, Fortier W, Burkle FM: Development of a triage protocol for critical care during an influenza pandemic. CMAJ 2006, 175:1377-1381.

12. Hospital Incident Command System, Emergency Medical Services Authority, State of California. October 2006 [http:// www.emsa.ca.gov/hics/hics.asp].

13. National Incident Management System Integration Center, Federal Emergency Management Agency [http://www.fema. gov/emergency/nims/index.shtm]

14. Barbera J, Macintyre A: Medical Surge Capacity and Capability: A Management System for Integrating Medical and Health Resources During Large-Scale Emergencies, August 2004. The CNA Corporation. [http://www.cna.org/documents/mscc_aug2004.pdf].

15. Barbera J, Macintyre A: Medical and Health Incident Management System: A Comprehensive Functional System Description for Mass Casualty Medical and Health Incident Management, December 2002. George Washington University Institute for Crisis, Disaster, and Risk Management. [http://www.gwu.edu/ icdrm/ publications/MaHIM\%20V2\%20final\%20report\%20sec\%202.pdf].

16. Saffle JR, Gibran N, Jordan M: Defining the ratio of outcomes to resources for triage of burn patients in mass casualties. $J$ Burn Care Rehabil 2005, 26:478-482.

17. Koenig KL, Goans RE, Hatchett RJ, Mettler FA Jr., Schumacher TA, Noji EK, Jarrett DG: Medical treatment of radiological casualties: current concepts. Ann Emerg Med 2005, 45:643-652.

18. Turai I, Veress K, Gunalp B, Souchkevitch G: Medical response to radiation incidents and radionuclear threats. BMJ 2004, 328:568-572.

19. Cone DC, MacMillan DS: Mass-casualty triage systems: a hint of science. Acad Emerg Med 2005, 12:739-741.

20. Cone DC, Koenig KL: Mass casualty triage in the chemical, biological, radiological, or nuclear environment. Eur J Emerg Med 2005, 12:287-302.

21. Beekley AC, Starnes BW, Sebesta JA: Lessons learned from modern military surgery. Surg Clin North Am 2007, 87:157184 , vii.

22. Eastridge BJ, Owsley J, Sebesta J, Beekley A, Wade C, Wildzunas $R$, Rhee $P$, Holcomb J: Admission physiology criteria after injury on the battlefield predict medical resource utilization and patient mortality. J Trauma 2006, 61:820-823.

23. King DR, Patel MB, Feinstein AJ, Earle SA, Topp RF, Proctor KG: Simulation training for a mass casualty incident: two-year experience at the Army Trauma Training Center. I Trauma 2006, 61:943-948.

24. Challen K, Bright J, Bentley A, Walter D: Physiological-social score (PMEWS) vs. CURB-65 to triage pandemic influenza: a comparative validation study using community-acquired pneumonia as a proxy. BMC Health Serv Res 2007, 7:33.

25. Chaharaein B, Omar AR, Aini I, Yusoff K, Hassan SS: Detection of $\mathrm{H} 5, \mathrm{H} 7$ and $\mathrm{H} 9$ subtypes of avian influenza viruses by multiplex reverse transcription-polymerase chain reaction. Microbiol Res 2007 Feb 28; [Epub ahead of print].

26. Falsey AR, Murata $Y$, Walsh EE: Impact of rapid diagnosis on management of adults hospitalized with influenza. Arch Intern Med 2007, 167:354-360.

27. American College of Emergency Physicians: Code of ethics for emergency physicians. Ann Emerg Med 1997, 30:365-372.

28. Society of Critical Care Medicine Ethics Committee: Consensus statement on the triage of critically ill patients. JAMA 1994, 271:1200-1203.

29. University of Toronto Joint Centre for Bioethics, Pandemic Influenza Working Group: Stand on Guard for Thee: Ethical Considerations in Preparedness Planning for Pandemic Influenza, November 2005. [http://www.utoronto.ca/jcb/home/documents/ pandemic.pdf].

30. Iserson KV, Pesik N: Ethical resource distribution after biological, chemical, or radiological terrorism. In Cambridge Quarterly of Healthcare Ethics. Vol. 12. Cambridge, UK: Cambridge University Press; 2003:455-465.

31. Pesik N, Keim ME, Iserson KV: Terrorism and the ethics of emergency medical care. Ann Emerg Med 2001, 37:642-646. 
32. Alexander GC, Werner RM, Ubel PA: The costs of denying scarcity. Arch Intern Med 2004, 164:593-596.

33. Daniels N, Sabin J: Setting Limits Fairly: Can We Learn to Share Scarce Medical Resources? New York, NY: Oxford University Press; 2002.

34. Eschun GM, Jacobsohn E, Roberts D, Sneiderman B: Ethical and practical considerations of withdrawal of treatment in the intensive care unit. Can J Anaesth 1999, 46:497-504.

35. McKneally MF, Dickens BM, Meslin EM, Singer PA: Bioethics for clinicians: 13. Resource allocation. Can Med Assn J 1997, 157: 163-167.

36. Iserson KV: Principles of biomedical ethics. Emerg Med Clin North Am 1999, 17:283-306.

37. Derse AR: Law and ethics in emergency medicine. Emerg Med Clin North Am 1999, 17:307-325.

38. Society of Critical Care Medicine Ethics Committee: Attitudes of critical care medicine professionals concerning distribution of intensive care resources. Crit Care Med 1994, 22:358-362.

39. American Medical Association Council on Ethical and Judicial Affairs: Ethical considerations in the allocation of organs and other scarce medical resources among patients. Arch Intern Med 1995, 155:29-40

40. Gostin LO, Saprin JW, Teret SP, Burris S, Mair JS, Hodge JG Jr., Vernick JS: The Model State Emergency Health Powers Act: planning for and response to bioterrorism and naturally occurring infectious diseases. JAMA 2002, 288:622-628.

41. Hick JL, Hanfling D, Burstein JL, DeAtely C, Barbisch D, Bogdan G, Cantrill S: Healthcare facility and community strategies for patient care surge capacity. Ann Emerg Med 2004, 44:253261.

42. Joint Commission on Accreditation of Healthcare Facilities: Surge Hospitals: Providing Safe Care in Emergencies. Chicago, IL: Joint Commission on Accreditation of Healthcare Facilities; 2006. [http://www.jcrinc.com/generic.asp?durki=11627\&site=11\&return $=$ http://www.ahrq.gov/research/altstand/405].

43. Gomersall CD, Tai DY, Loo S, Derrick JL, Goh MS, Buckley TA Chua C, Ho KM, Raghavan GP, Ho OM, et al:: Expanding ICU facilities in an epidemic: recommendations based on experience from the SARS epidemic in Hong Kong and Singapore. Intensive Care Med 2006, 32:1004-1013.

44. Posner Z, Admi H, Menashe N: Ten-fold expansion of a burn unit in mass casualty: how to recruit the nursing staff. Disaster Manag Response 2003, 1:100-104.

45. Vincent JL, Moreno R, Takala J, Willatts S, De Mendonca A, Bruining $\mathrm{H}$, Reinhart CK, Suter PM, Thijs LG: The SOFA (sepsisrelated organ failure assessment) score to describe organ dysfunction/failure. On behalf of the Working Group on Sepsis-Related Problems of the European Society of Intensive Care Medicine. Intensive Care Med 1996, 22:707-710.

46. Herridge MS: Prognostication and intensive care unit outcome: the evolving role of scoring systems. Clin Chest Med 2003, 24:751-762.

47. Moreno R, Vincent JL, Matos R, Mendonça A, Cantraine F, Thijs L, Takala J, Sprung C, Antonelli M, Bruining $\mathrm{H}$, et al.: The use of maximum SOFA score to quantify organ dysfunction/failure in intensive care. Results of a prospective, multicentre study. Working Group on Sepsis related Problems of the ESICM. Intensive Care Med 1999, 25:686-696.

48. Vincent JL, de Mendonça A, Cantraine F, Moreno R, Takala J, Suter PM, Sprung CL, Colardyn F, Blecher S: Use of the SOFA score to assess the incidence of organ dysfunction/failure in intensive care units: results of a multicenter, prospective study. Crit Care Med 1998, 26:1793-1800.

49. Peres Bota D, Melot C, Lopes Ferreira F, Nguyen Ba V, Vincent $\mathrm{JL}$ : The multiple organ dysfunction score (MODS) versus the sequential organ failure assessment (SOFA) score in outcome prediction. Intensive Care Med 2002, 28:1619-1624.

50. Pettila V, Pettila M, Sarna S, Voutilainen P, Takkunen O: Comparison of multiple organ dysfunction scores in the prediction of hospital mortality in the critically ill. Crit Care Med 2002, 30:1705-1711.

51. Lemeshow S, Klar J, Teres D, Avrunin JS, Gehlbach SH, Rapoport $\mathrm{J}$, Rué M: Mortality probability models for patients in the intensive care unit for $\mathbf{4 8}$ or $\mathbf{7 2}$ hours: a prospective, multicenter study. Crit Care Med 1994, 22:1351-1358.

52. Lemeshow S, Teres D, Klar J, Avrunin JS, Gehlbach SH, Rapoport $\mathrm{J}$ : Mortality probability models based on an international cohort of intensive care unit patients. JAMA 1993, 270:24782486.

53. Lemeshow S, Le Gall JR: Modeling the severity of illness in ICU patients: a systems update. JAMA 1994, 272:1049-1055.

54. Marshall JC, Cook DJ, Christou NV, Bernard GR, Sprung CL, Sibbald WJ: Multiple organ dysfunction score: a reliable descriptor of a complex clinical outcome. Crit Care Med 1995, 23:1638-1652.

55. Cook R, Cook D, Tilley J, Lee K, Marshall J, Canadian Critical Care Trials Group: Multiple organ dysfunction: baseline and serial component scores. Crit Care Med 2001, 29:2046-2050.

56. Zygun DA, Laupland KB, Fick GH, Sandham JD, Doig CJ: Limited ability of SOFA and MOD scores to discriminate outcome: a prospective evaluation in 1,436 patients. Can J Anaesth 2005, 52:302-308

57. Trachsel D, McCrindle BW, Nakagawa S, Bohn D: Oxygenation index predicts outcome in children with acute hypoxemic respiratory failure. Am J Respir Crit Care Med 2005, 172:206-211.

58. Venkataraman ST, Khan N, Brown A: Validation of predictors of extubation success and failure in mechanically ventilated infants and children. Crit Care Med 2000, 28:2991-2996.

59. Monchi M, Bellenfant F, Cariou A, Joly LM, Thebert D, Laurent I, Dhainaut JF, Brunet $F$ : Early predictive factors of survival in the acute respiratory distress syndrome. A multivariate analysis. Am J Respir Crit Care Med 1998, 158:1076-1081.

60. Peters MJ, Tasker RC, Kiff KM, Yates R, Hatch DJ: Acute hypoxemic respiratory failure in children: case mix and the utility of respiratory severity indices. Intensive Care Med 1998, 24:699705.

61. Fault-tolerant system as defined by Wikipedia. [http://en. wikipedia.org/wiki/Graceful_degradation]. 